\title{
Intestinal permeability to polyethyleneglycol 600 in relation to macromolecular 'closure' in the neonatal pig
}

\author{
B WESTRÖM, J SVENDSEN, AND C TAGESSON \\ From the Department of Zoophysiology, University of Lund, Department of Farm Buildings, \\ Swedish University of Agricultural Sciences, Lund, and Department of Clinical Chemistry, Linköping \\ University, Sweden
}

SUMmaRY The intestinal permeability of different sized molecules in the neonatal pig was investigated. Piglets of varying age $(0-168 \mathrm{~h})$ were given a mixture of different sized polyethyleneglycols (414-942 dalton polyethyleneglycols) together with ovalbumin and bovine serum albumin by stomach tube, and the serum concentrations were determined two hours after feeding. Considerable amounts of ovalbumin and bovine serum albumin were found in the serum of animals up to 24 hours of age, whereas very little or none at all was found in sera from older animals. By contrast, an intestinal permeability barrier to polyethyleneglycols in the 414-942 dalton range was found not only in the older animals but in all pigs investigated, including the newborn, unsuckled. In addition, the permeability barrier to polyethyleneglycols was found in a pig which was starved to prevent macromolecular closure and, therefore, absorbed considerable amounts of bovine serum albumin and ovalbumin. These findings indicate that 414-942 dalton polyethyleneglycols cross the intestinal mucosa at different rates due to size regardless of age of the animals and regardless of whether the mucosa is permeable to protein or not. This suggests that low molecular weight molecules like 414-942 dalton polyethyleneglycols and macromolecules (proteins) cross the neonatal gut wall through different routes.

During the neonatal period in mammalian species the intestinal mucosa is immature, as compared with the adult, for varying time periods. Thus, during this period, the mucosa is permeable to macromolecules so that large quantities of both antibodies and antigens may be transported across the mucosa into the systemic circulation. ${ }^{12}$ In the newborn pig, virtually all proteins coming in contact with the mucosa are absorbed into the blood circulation in large amounts. ${ }^{13}$ This period of enhanced uptake lasts only for about 24 hours after onset of colostrum ingestion; the intestine then 'closes' to prevent further massive uptake of macromolecules. Although this 'closure' phenomenon has received much attention, the underlying mechanisms remain largely obscure and little is known about how 'closure' affects the permeability to molecules of

Address for correspondence: C. Tagesson. MD. Department of Clinical Chemistry, Linköping University, S-581 85 Linköping, Sweden.

Received for publication 18 July 1983 varying size, charge and shape.

This study deals with the intestinal permeability to different sized molecules in the neonatal pig. It was anticipated that the use of a spectrum of different sized molecules as permeability probes in each animal under study would minimise the influence of irrelevant variables and facilitate analysis of the underlying mechanism. We therefore studied the peremeability to low molecular weight molecules in the 414-942 dalton range (polyethyleneglycol 600) together with the macromolecules ovalbumin $\left(M_{w}=43,000\right)$ and bovine serum albumin $\left(M_{w}=69,000\right)$, before and after macromolecular closure. The results indicate that polyethyleneglycols in the 414-942 dalton range cross the intestinal mucosa at different rates regardless of whether the mucosa is permeable or not to ovalbumin and bovine serum albumin. It appears, therefore, that the intestinal permeability barrier to polyethyleneglycols in the 414-942 dalton range is at hand already at birth and that it is unrelated to macromolecular closure. 


\section{Methods}

MATERIALS

Chemicals and equipment

Polyethyleneglycol with an average molecular weight of about 600 (polyethyleneglycol $600, \mathrm{HO}$ $\left.\left(\mathrm{CH}_{2}-\mathrm{CH}_{2} \mathrm{O}\right)_{n} \mathrm{H} \mathrm{n}=9-21\right)$ was obtained from $\mathrm{BDH}$ Chemicals Ltd, Poole, England. The liquid chromatograph was a HSRI 931 (Optilab AB, Stockholm, Sweden), equipped with a 902 C refractometer and a $10 \mathrm{~mm}$ measuring cell. The column used was Apex C8 $(250 \times 4.4 \mathrm{~mm}$, Jones Chromatography Ltd, Llandbradach, Great Britain). Peak areas (in $\mu \mathrm{Vs}$ ) and retention times were obtained by means of an LDC 304-50 computing integrator (Hugo Tillqvist $\mathrm{AB}$, Solna, Sweden).

\section{Animals}

In all, 26 neonatal pure breed Swedish Landrace piglets $^{4}$ from five litters, aged 0 (newborn unsuckled) to seven days were used in the study. Apart from the newborn (unsuckled), the piglets were kept together with their dams and thus had free access to the sow's colostrum/milk until the experimental feeding. In addition, three unsuckled piglets were taken from their dams immediately after birth and kept in a heated nursing cage with free access to a solution of glucose $(3 \cdot 2 \mathrm{~g} / \mathrm{l}), \mathrm{NaCl}$ $(1.2 \mathrm{~g} / \mathrm{l})$ and $\mathrm{Fe}$-glutamat $(3.5 \mathrm{~g} / \mathrm{l})(\mathrm{Fe}-\mathrm{max}$, Peter Möller a/s, Oslo, Norway).

\section{PROCEDURES}

The test feeding solution fed at various times from birth $(0 \mathrm{~h}$, to $168 \mathrm{~h}$ after birth) consisted of $20 \%$ polyethyleneglycol $600(\mathrm{w} / \mathrm{w}), 2 \%$ bovine serum albumin (bovine serum albumin, fraction V, Sigma, St Louis, USA) and 2\% ovalbumin (Ovalb, Sigma) in $0.9 \%$ saline. The solution was given $(10 \mathrm{ml} / \mathrm{kg}$ body weight) by stomach tube and the piglets were kept in separate cages allowing urine sampling. Two hours after the experimental feeding, a blood sample was taken by puncture of the anterior vena cava and urine withdrawn by puncture of the urinary bladder. ${ }^{5}$ Serum and urine (pooled from the cage and the bladder puncture) were stored frozen at $-20^{\circ} \mathrm{C}$ until analysed.

\section{ANALYSIS}

For polyethyleneglycol analysis, $1 \mathrm{ml}$ serum or urine was applied to kieselghur (Extrelut ${ }^{\mathrm{R}}$, E Merck, Darmstadt, West Germany) and eluted with $6 \mathrm{ml}$ chloroform. The eluate was evaporated under air, $1 \mathrm{ml}$ methanol:water (40:60) added, and the test tube put in a $37^{\circ} \mathrm{C}$ waterbath for 10 minutes. The tube content was then mixed with a Vortex mixer and filtered through a Millipore HA $0.45 \mu \mathrm{m}$ filter using a MF-1 complete microfilter sample system. Polyethyleneglycols in the extracted samples were determined through reversed phase high performance liquid chromatography, using refractive index detection to identify the different-sized molecules. Details concerning the chromatographic conditions are given in the legend to Figure 1.

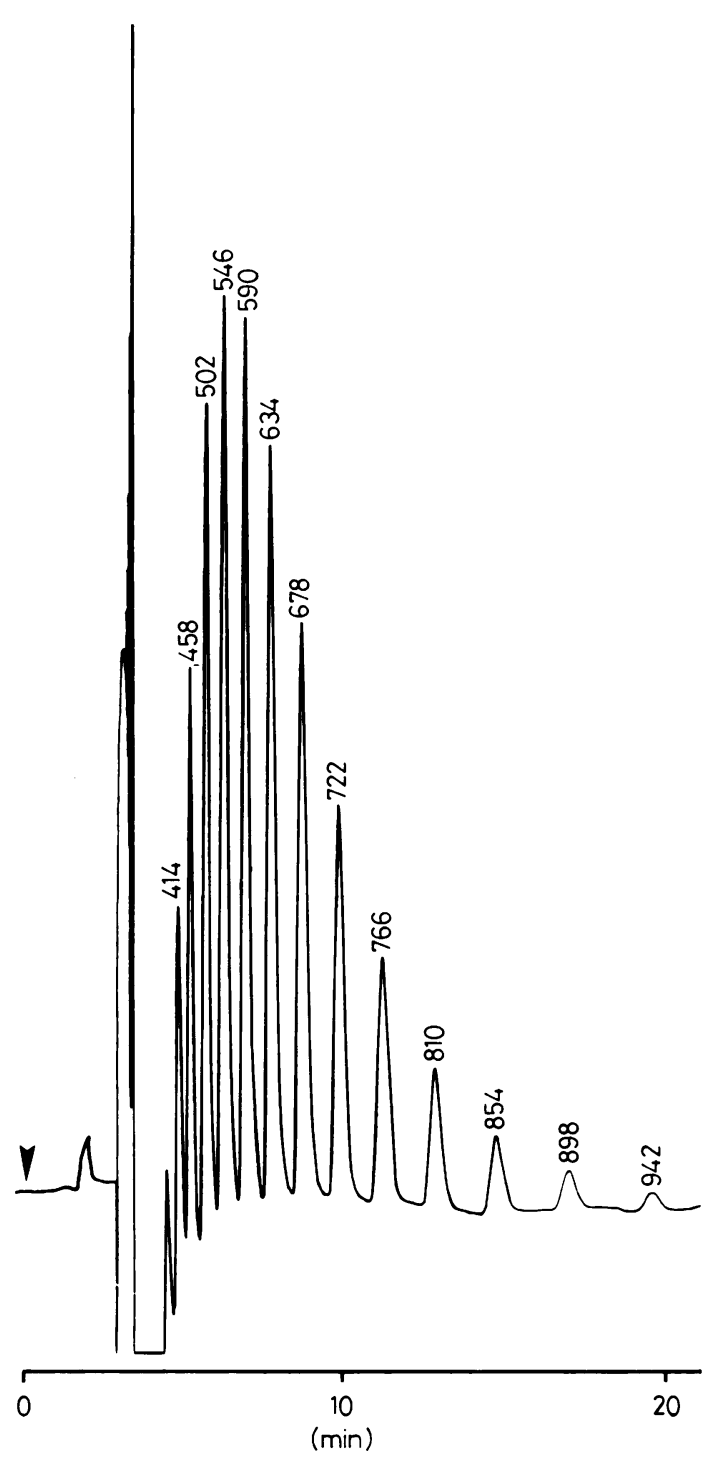

Fig. 1 Reversed phase HPLC resolution of different molecular species in polyethyleneglycol 600. Sample volume, $100 \mu \mathrm{l}$; flow rate, $0.88 \mathrm{ml} / \mathrm{min}$; mobile phase, methanol:water (40:60); pressure, $10.3 \mathrm{MPa}$; temperature, $28^{\circ} \mathrm{C}$; recorder speed, $0.5 \mathrm{~cm} / \mathrm{min}$. 
Quantitation of bovine serum albumin and ovalbumin in serum was performed by electroimmunoassay. ${ }^{6}$ Antiserum to bovine serum albumin was obtained from Miles Laboratories (Freehold, USA) whereas specific rabbit antiserum to ovalbumin was produced according to Jakobsson $e t$ $a .^{7}$

\section{Results}

PERMEABILITY TO BOVINE SERUM ALBUMIN AND OVALBUMIN

The intestinal permeability to macromolecules in piglets of ages from birth up to seven days was monitored by determining the serum concentrations of bovine serum albumin and ovalbumin two hours after gastric load (Fig. 2). The serum levels of both markers were essentially parallel throughout the varying ages investigated and showed that large amounts of the proteins were absorbed up to 24 hours after birth. Thereafter, only inconspicious or undetectable amounts were absorbed. These findings reflect the intestinal 'closure' for macromolecular transmission that occurs at this time. In piglets fed glucose for up to 42 hours after birth, however, both bovine serum albumin and ovalbumin were absorbed (Fig. 2).

PERMEABILITY TO POLYETHYLENEGLYCOL 600 . The intestinal permeability to polyethyleneglycols in the 502-942 dalton range is illustrated by the absorption-molecular weight profiles in Figure 3 . Thus, the serum concentrations of larger polyethyleneglycols in the spectrum were consistently lower than the corresponding concentrations of smaller polyethyleneglycols in all piglets investigated, indicating that larger polyethyleneglycols were less absorbed into the circulation than smaller ones, regardless of age. Also, the serum concentrations of larger polyethyleneglycols were lower than of smaller polyethyleneglycols in a 24 hour old pig which was fed glucose instead of colostrum to prevent closure to macromolecules (Fig. 3c).

The permeability to polyethyleneglycols is also illustrated by the absorption molecular weight profiles in Figure 4. Here, the absorption of each molecular weight component has been assessed as urinary recovery after gastric load. Urinary recoveries of larger polyethyleneglycols were consistently lower than those of smaller polyethyleneglycols in all piglets investigated, again indicating that larger polyethyleneglycols were less absorbed than smaller polyethyleneglycols, regardless of age.

\section{Discussion}

The mucosal membranes of the adult mammalian gut are relatively impermeable to large molecules. On the other hand, large amounts of macromolecules - for example. immunoglobulins, can be transmitted across the neonatal gut of several

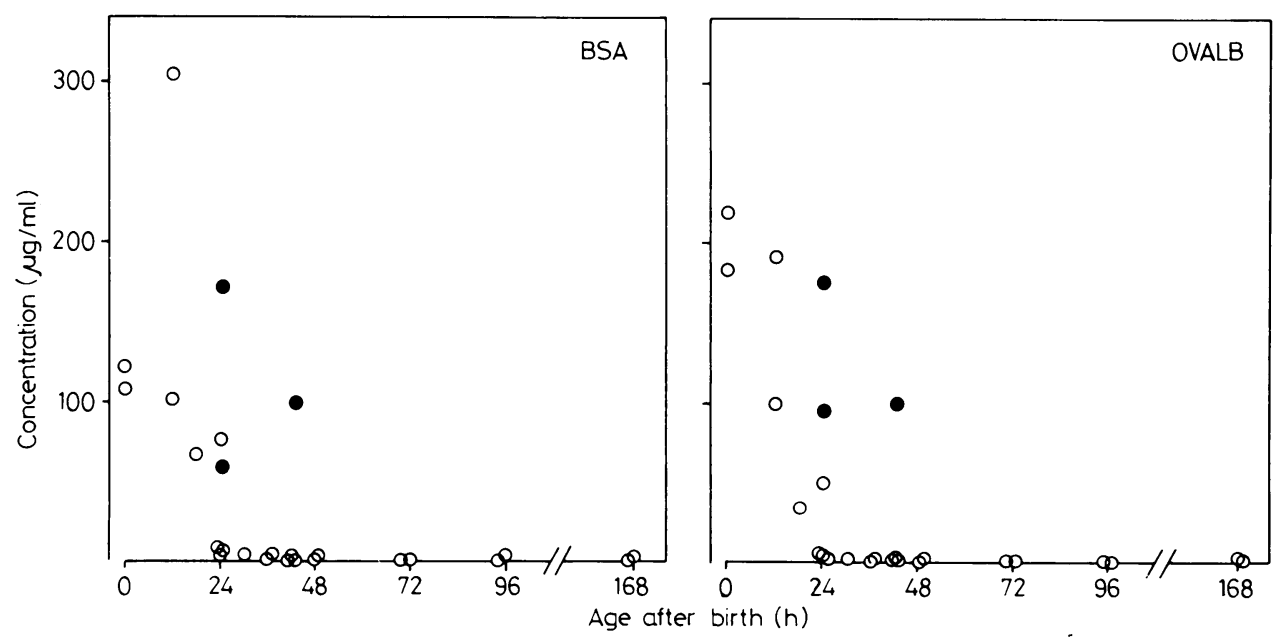

Fig. 2 Intestinal absorption of bovine serum albumin (BSA) and ovalbumin (Ovalb) in different aged neonatal pigs. Absorption was measured as serum concentrations $(\mu \mathrm{g} / \mathrm{ml})$ of proteins two hours after feeding neonatal pigs that either had had free access to colostrum ( $(0)$, or were fed glucose instead of colostrum $(\bullet)$. 
Fig. 3 Absorption molecular weight profiles for polyethyleneglycol 600 in pigs of varying age. Absorption of each molecular weight component was assessed as serum concentration 2 hours after gastric load. (a) pigs aged $0-18$ hours, (b) pigs aged 36168 hours, (c) a pig aged 24 hours which was fed glucose from birth, (d) pigs aged 24 hours. In (a) and (c) all pigs show macromolecular absorption while in (b) and (d) the pigs show macromolecular closure as monitored with the markers BSA and ovalbumin (cf. Figure 2). Vertical bars indicate standard deviation.
Fig. 4 Absorptionmolecular weight profiles for polethyleneglycol 600 in pigs of varying age. Absorption of each molecular weight component was assessed as the recovery in $2 \mathrm{~h}$ urine after gastric load. a-d, as in Figure 3.
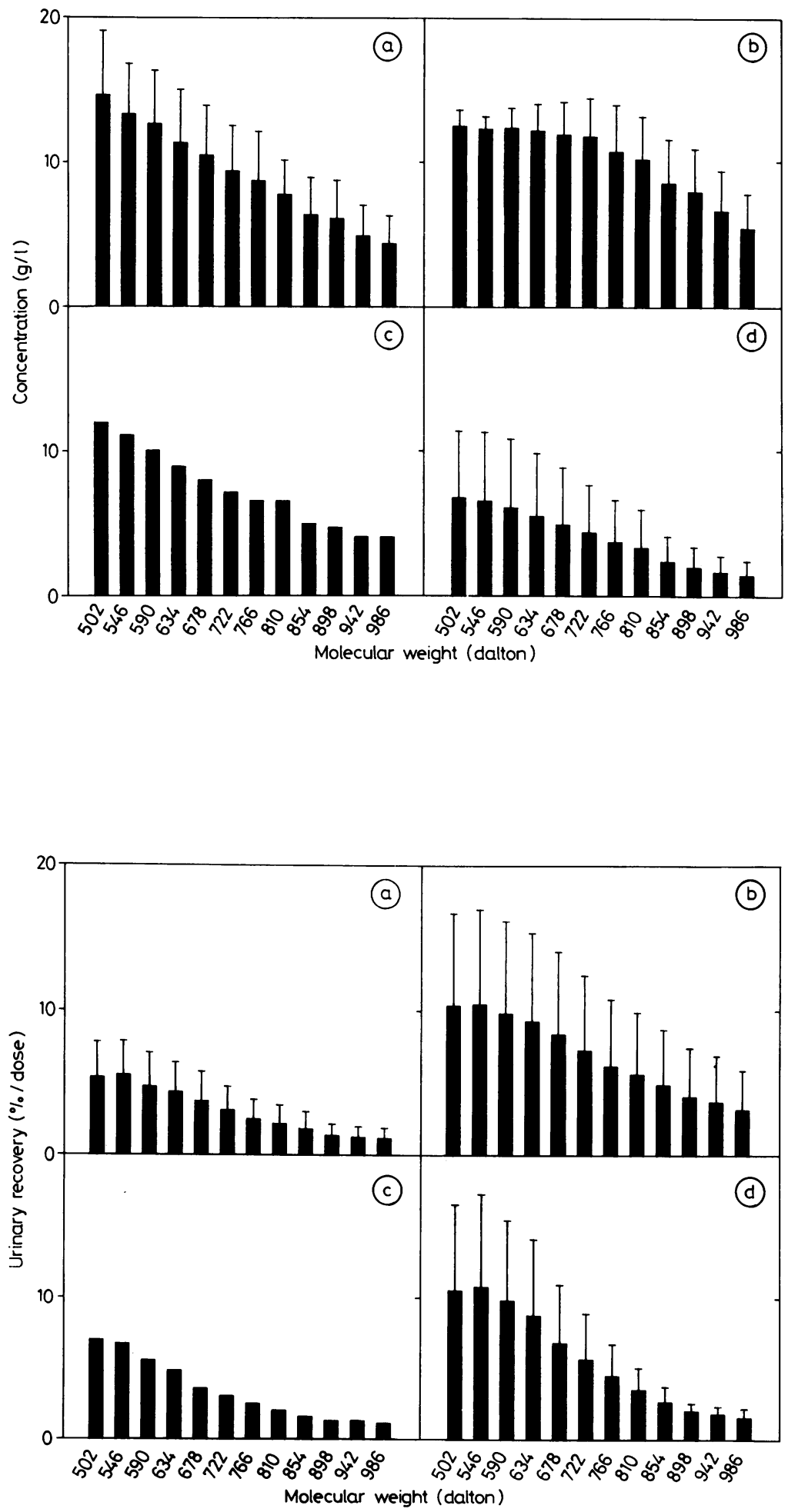
species. $^{12}$ Apparently the maturation of the mammalian gut involves a macromolecular 'closure', that is, a restriction in permeability to larger molecules. Also, if mixtures of different sized (370-1338 dalton) polyethyleneglycols are given to adult humans ${ }^{89}$ or pigs, ${ }^{8}$ the urinary recovery of the different sized molecules is inversely related to molecular size: the larger the molecule, the less the urinary recovery. On the other hand, if 282-1206 dalton polyethyleneglycols are given intravenously to adult pigs the larger polyethyleneglycols of the spectrum are recovered in the urine to the same or even a greater extent than the smaller. ${ }^{10}$ These findings indicate that low molecular weight polyethyleneglycols cross the mature gut mucosa at different rates owing to their different molecular sizes - that is, the adult mucosa restricts permeation because of size also in the 370-1338 dalton range.

The experiments reported in this communication aimed at studying whether the gut mucosa of the newborn, too, restricts permeation because of size in the low molecular weight (414-942 dalton) range. Alternatively, the more mature mucosa might have acquired this property along with the closure to macromolecular passage.

The investigation confirms earlier findings that intestinal closure to macromolecules occurs at an age of about 24 hours after birth in pigs, as after that, the two marker proteins were absorbed only in trace amounts. The investigation further indicates that differences in intestinal permeability to low molecular weight probes such as 414-942 dalton polyethyleneglycols are at hand already at birth, as larger polyethyleneglycols were less absorbed than smaller also in the newborn, unsuckled pig. Such a difference in permeability was also found in the older animals that showed intestinal closure to bovine serum albumin and ovalbumin, and in the piglets fed glucose that did not show intestinal closure. It appears, therefore, that the intestinal permeability barrier to 414-942 dalton polyethyleneglycols is unrelated to macromolecular closure, and that an adult pattern of low molecular nutrient absorption is at hand already at birth in the piglet.

We have thus obtained some evidence to indicate that polyethyleneglycols in the 414-942 dalton range cross the intestinal mucosa at different rates because of size regardless of whether the mucosa is permeable or not to protein. Although further implications of these findings are unclear, one particular point may be stressed. The findings suggest that 414-942 dalton polyethyleneglycols and proteins permeate the neonatal gut wall through different routes. Thus, whereas proteins are taken up largely via endocytosis, ${ }^{11} 12$ polyethyleneglycols may be able to pass through small 'pores' in the lipid membrane of the enterocyte or by channels associated with the functional complexes between adjacent enterocytes. If so, 414-942 dalton polyethyleneglycols are not likely to be relevant permeability probes when assessment of intestinal permeability to proteins is aimed at. If the 'permeability barrier' to low molecular weight polyethyleneglycols is unrelated to any macromolecular uptake, polyethyleneglycols absorption tests are not likely to reveal, if present, an increased intestinal permeability to potentially antigenic material. This should be borne in mind when intestinal permeability determinations are pursued in view of the concept that altered gut permeability could underlie the pathogenesis of allergic, rheumatic and various gastrointestinal diseases. ${ }^{2} 13$

This work was supported by The Director A. Påhlsson Foundation, The Swedish Natural Science Research Council, The Swedish Council for Forestry and Agricultural Research, The Swedish University of Agricultural Sciences, The Swedish National Association against Rheumatism and The Swedish Medical Research Council (grant B8317X-05983-03A).

\section{References}

1 Brambell FWR. The transmission of passive immunity from mother to young. Amsterdam: North-Holland, 1970.

2 Walker AW. Intestinal transport of macromolecules. In: Johnson LR, ed Physiology of the gastrointestinal tract. New York: Raven Press, 1981.

3 Carlsson LCT, Weström BR, Karlsson BW. Intestinal absorption of proteins by the neonatal piglet fed on sow's colostrum with either natural or experimentally eliminated trypsin-inhibiting activity. Biol Neonate 1980; 38: 309-20.

4 Jeppsson M, Svendsen J, Andreasson B. Behaviour studies of 'loose' and 'fixed' dry sows maintained under the same husbandry, feeding and stable conditions. Swedish University of Agricultural Sciences, Department of Farm Buildings report 1980; 10.

5 Parker R, Williams P, Aherne F, Young B. An efficient method for collecting urine from neonatal pigs. Can $J$ Anim Sci 1979; 59: 457-8.

6 Laurell C-B. Quantitative estimation of proteins by electrophoresis in agarose gel containing antibodies. Anal Biochem 1966; 15: 45-52.

7 Jakobsson I, Lindberg T, Benediktsson B. In vitro digestion of cow's milk proteins by duodenal juice from infants with various gastrointestinal disorders. $J$ Pediat Gastroenterol Nutr 1982; 1: 183-91. 
8 Tagesson $\mathrm{C}$, Andersson $\mathrm{P} \AA$, Andersson T, Bolin T, Källberg M, Sjödahl R. Passage of molecules through the wall of the gastrointestinal tract. Measurement of intestinal permeability to polyethyleneglycols in the 634-1338 dalton range. (PEG $100(0)$. Scand $J$ Gastroenterol 1983; 18: 481-6.

9 Tagesson $\mathrm{C}$, Bengtsson $\mathrm{A}$. Intestinal permeability to different-sized polyethyleneglycols in patients with rheumatoid arthritis. Scand J Rheumatol 1983; 12: 124-8.

10 Tagesson C, Sjödahl R. Passage of molecules through the wall of the gastrointestinal tract. Urinary recovery of different-sized polyethyleneglycols after intravenous and intestinal deposition. Scand J Gastroenterol 1984. (In press.)

11 Kraehenbuhl JP, Campiche MA. Early stages of intestinal absorption of specific antibodies in the newborn. An ultrastructural, cytochemical and immunological study in the pig, rat and rabbit. $J$ Cell Biol 1969; 42: 345-65.

12 Hardy RN, Hockaday AR, Tapp RL. Observations on the structure of the small intestine in foetal, neonatal and suckling pig. Phil Trans $R$ Soc B 1971; 259: 517-31.

13 Tagesson $C$, Magnusson KE, Sundqvist T. Intestinal permeability studies and human disease. Monogr Allergy 1981; 17: 250-72. 